Pinkoane et al., Afr J Tradit Complement Altern Med. (2012) 9(3S):12-18

\title{
A MODEL FOR THE INCORPORATION OF THE TRADITIONAL HEALERS INTO THE NATIONAL HEALTH CARE DELIVERY SYSTEM OF SOUTH AFRICA
}

\author{
*Martha G. Pinkoane ${ }^{a}$, Minrie Greeff ${ }^{\mathrm{b}}$, Magdalena P. Koen ${ }^{\mathrm{b}}$ \\ Faculty of Applied and Computer Sciences, Biosciences, Nursing, Vaal University of Technology, \\ Vanderbijlpark, South Africa. ${ }^{b}$ School of Nursing Science, Potchefstroom campus of the North-West \\ University, Potchefstroom. \\ *E-mail: martha@vut.ac.za
}

\begin{abstract}
In South Africa the patient uses both the traditional healers and biomedical personnel's services out of need for the best healing therapy to fulfil his/ her health needs. Failure of one to yield the expected results leads to the use of the other. This shunting back and forth prompted the researcher to undertake research and formulated a model demonstrating how the traditional healers can be incorporated into the National Health Care Delivery System of South Africa. The research used both qualitative and theory generating designs to attain the set objective. Firstly, a qualitative research design used semi-structured interviews to investigate the perceptions and attitudes of biomedical personnel, traditional healers, patients and policy makers, regarding the process of incorporation. A non-probable purposive voluntary sample was used, selection was done according to a set criteria. Data was analysed and the results of phase one as well as initial literature review were used to construct a conceptual framework for the model. Secondly, a theory generating design was employed using the three phases of Dickoff, James and Wiedenbach (1968:435) to formulate a model which was systematically, logically and consistently conceptualized. In evaluation of this model a predetermined criteria was used. The results showed that the constructed model demonstrated the government formulating policy to legalize traditional healing and affording the traditional healers legal authority to be official partners to the biomedical personnel and avail the quality health care services that fulfils the patients health needs using the primary health care approach.
\end{abstract}

Key words: Incorporation, traditional healer, biomedical personnel, patients, model, National Health Care Deliver System.

\section{Introduction}

In South Africa $80-90 \%$ of black patients uses both the traditional healers and the biomedical personnel's services out of the need for the best healing therapy to fulfil his/her health needs (Abdool Karim, Ziqubu- Page \& Arendse, 1994). This use creates a motion of shunting to and from between the two health care providers, where both systems stand in conflict with one another and the patient find himself caught in the middle (Peu, Hatting \& Troskie, 2001).

The possibility of traditional healers and biomedical personnel functioning together existed since the eighties. The two groups met in Johannesburg in 1986 to discuss ways by which functioning together can be established (Zungu, 1992:24). A series of meetings and discussions followed after which, came the promulgation of the Chiropractors Homeopaths and Allied Health Services Professionals Act of 1996, the Traditional Health Practitioners Act of 2003 amended in 2007. These Acts gives the traditional healers their due legal recognition but does not include them as part of health care providers, based on the premise that traditional medicines need to be scientifically tested first, before the traditional healer can be allowed to work with the biomedical personnel (Department of Health, 1996; 1997; 2003; 2007).

This research was initiated with the purpose of formulating a model for the incorporation of the traditional healers into the National Health Care Delivery System of South Africa (Pinkoane, Greeff and Williams, 2001). The researcher divided the research into two stages, namely, first stage, qualitative and second stage theory generating.

\section{Methodology \\ Stage one}

In the first stage a qualitative, exploratory, descriptive and contextual research design was used. The study was conducted in the regions of the three provinces of North West, Gauteng and Free State in South Africa. There were two objectives to be achieved in the first stage, and the last objective was for this article which is formulating a model for the incorporation of traditional healers into the National Health Care System of South Africa. The first two objectives were attained based on the fact that the research questions as set out, were answered using the following research objectives: 1). To investigate the existing models for the incorporation of traditional healers into National Health Care Delivery Systems. This was attained by conducting a critical literature review which revealed that traditional healers are used in health care settings (Pinkoane, Greeff and Koen, 2005a). In the West the traditional healer is regarded as the complementary or alternative health 
practitioner and in the East and Africa he/she is still the traditional healer whose services are used simultaneously with those of the biomedical personnel. South Africa recognizes the traditional healer but he/she is not used as an official health care provider except for in projects which had been initiated to explore the potential of a working relationship (Pinkoane, et al., 2005 a). The concepts derived from the literature study are that traditional healers are to be autonomous, self regulate and control their own practice like the biomedical personnel. That licensing should be left to their own council, reciprocal education and training should be fostered. The government was under pressure to review the process of legalization and its implications on self control, the Traditional Health Practitioners' Act of 2003 (amended in 2007) was not explicit about the process of working together.

2). To explore the perceptions and attitudes of the traditional healers, biomedical personnel, patients and policy makers regarding the process for the incorporation of traditional healers into the National Health Care Delivery System of South Africa, as well as their views on how this incorporation should be achieved.

As a qualitative research design was followed, hundred participants were selected by means of non probable purposive voluntary sampling (Burns \& Grove, 1997), data saturation determined the number of participants. The criteria used to select each group differed according the specific requirements, and for the traditional healers, it was to be according to the definition of World Health Organisation's definition (WHO, 1987; 2000). The biomedical personnel were all to be members of their different professional organizations, for the nurses it had to be the South African Nursing Council. For the doctors, psychiatrists, psychologists and pharmacists, the Health Professions Council. The patients had to be those that use both traditional healing therapies simultaneously with the biomedical therapies. The policy makers had to be either health professionals and/or officials in the Provincial Health Departments designated with the job of managing health care services in the districts/ regions within the identified province. They were all to have been prepared and available to participate in the study and had given informed consent after receiving the reasons and procedures of the research.

Data was collected by means of conducting semi-structured interviews in English, Afrikaans, Tswana, South Sotho and Zulu/Xhosa mix with all the participants in the three identified provinces in South Africa. Field notes were recorded after each interview session. Data analysis was achieved by verbatim transcriptions and translated into English. The translations were later evaluated by a qualified language practitioner. Content analysis was used employing the method of open coding as described by Tesch in Cresswell (1990). The use of double coding was employed whereby a nurse specialist or an expert co-coder decoded independently of the researcher. The co-coder received copies of the transcriptions, field notes and a work protocol, that indicated the objectives of the research, the questions as asked to all the participants as well as the guide of steps as described in the protocol, using a method of open- coding. The researcher met the co-coder to discuss the findings, reach consensus and to finalise the data.

Ethical principles were applied according to the guidelines of the Democratic Nurses Organisation of South Africa (DENOSA, 1997) and the Department of Health (DOH, 2000). This objective was also attained because the results demonstrated an agreement of all the stake holders that the traditional healers are available to provide services for the patients. The government was identified as responsible for paving the way by stipulating in policy the process of working together. That health care settings or structures should be erected by government to enhance this process of working together (Pinkoane, et al., $2005 \mathrm{~b}$, $\mathrm{c}$, and e).

The last objective of this research, formulating a model for the realization of the incorporation of traditional healers into the National Health Care Delivery System of South Africa, used the approach of Dickoff, James and Wiedenbach (1968:236) as described by Greeff (1991) for the purpose of theory generation.

\section{Second stage}

This is the second stage for theory generation to formulate a model for the incorporation of traditional healers into the National Health Care System of South Africa. The methodology applied uses the first three levels of the approach of Dickoff, et al., (1968)'s theory which were, factor isolating, factor relating and situation relating. In level one factor isolating theory, concepts were identified, classified, defined and analysed. Level two, factor relating theory, relationships between concepts were delineated, and level three situation relating theory, the structure and process of the model was discussed.

\section{Factor Isolating theory}

In factor isolating theory the concepts were identified, classified, analysed and defined using the approach of Dickoff et al., (1968) and Walker and Avant (1995). Concepts are the most critical elements to consider when undertaking theory generation, based on the premise that they guide the process of investigation, which give direction to theory generation.

\section{Identification of concepts}

Concept identification is a process described by Chinn and Kramer (1995) as identifying those concepts that form the basic fabric of theory. In this case the words to identify concepts were effected by employing a critical literature review of international and national approaches for the incorporation process (Pinkoane et al.,2005 a) as well as undertaking a qualitative research that was exploratory, descriptive and contextual in nature (Burns \& Grove,1997). Enough knowledge about the perceptions and attitudes of the traditional healers, biomedical personnel, patients and policy makers regarding the incorporation of the traditional healers into the National Health Care Delivery System of South Africa, was gained (Pinkoane et al., 2005 b, c, 
e). The main concept identified was incorporation of traditional healers, and the associated concepts were: policy and organization; professional relationship; reciprocal education and training, referral system; scientific testing of traditional medicines; patients choice of health care respected and availing quality health care services.

\section{Concept classification}

Concept classification is sorting, categorizing, assigning names in terms of belonging to one kind as opposed to another. In concept classification concepts were sorted, put together and related one to the other according to their affinity. The approach of Greeff (1991) which used the survey list from Dickoff et al., (1968), was employed and includes the following:

- agency referring to the who or what that performs the activity;

- recipient referring to who or what receives the activity;

- framework means, the context within which the activity is performed;

- terminus refers to the end point of the activity;

- procedures of the activity refer to the actions undertaken;

- and dynamics as the energy source of the activity. The survey list, was thus used to construct the tentative conceptual framework, which according to Wilson (1989) is postulating relationships among concepts and permits empirical testing.

The activity incorporation was viewed as produced by the agent, which was the traditional healers and biomedical personnel and received by a recipient which was the patient. The path that leads the activity from agent to recipient, were procedures which were undertaken to lead the activity to the terminus, which is quality health care. Dickoff et al., (1968) further states that these activities are intimately related by pathways from one to another, as cited.

\section{Concept analysis and definition}

Concept analysis is described by Walker and Avant (1995) as a process where one clarifies, refines or sharpens concepts to better understand them. Wilson (1989) describes concept analysis as essentially a thinking process, where relevant variables or concepts are explored. The concepts are analysed, and investigated for differences and similarities in elements of the phenomena of interest within a theory. Some concepts are abstract in nature (Chinn \& Kramer, 1995), as is the main concept of the model "incorporation of traditional healers." Scientific language is used by researchers to find the meanings attributed to the main concept within the theory, therefore it is self explanatory that followers of the same framework find it easy to communicate with each other (Greeff, 1991).

\section{* Concept definition of the main concept "incorporation of the traditional healers"}

The definition was formulated from the analysis and the main elements as follows: Incorporation of traditional healers refers to a legally authorised process of bringing about the functioning of traditional healers and the biomedical personnel as two separate bodies made up of professionals and practitioners to work together under one health department in a multi-professional approach. They share the same aims and objectives focussed at fulfilling the patients' identified health and cultural needs. It is a two sided effort combining both treatment methods and best practices to form partnership in which each remain autonomous.

Factor Relating theory: formulation of the visual model for the incorporation of the traditional healers into the National Health Care Delivery System of South Africa

Factor relating theory is a level of theory where concepts are not seen in isolation but are linked in relation of one to the other. Hardy (1978:16) mention that to link concepts it becomes necessary to examine the relationship between their logical structure, because several relationships can exist between concepts in a theory and are better expressed in a form of a model. Chinn and Kramer (1995) is of meaning that in factor relating, concepts are correlated or associated in such a way that they become part of a larger meaningful situation. In a meaningful situation relationships are explored, and the overall structure of a theory and its components begin to emerge and take shape. The main relationships between concepts were formulated and a visual model created.

\section{Results}

A tentative visual model was constructed after the main and associated concepts were identified. The importance of such a visual model was to give the researcher a diagram for discussion with experts. The model was constructed in such a manner as to relate to the process and structure for the incorporation of traditional healers.

Dialogue was carried out with experts in model formulation and traditional healing, to agree on the delineated relationships. The purpose and value of the dialogue was not to invite objection and opposing views but to communicate ideas, knowledge, and through a medium of critical evaluation, review a better approach that could be used. 
Pinkoane et al., Afr J Tradit Complement Altern Med. (2012) 9(3S):12-18

After dialogue with experts, there was an endeavour to effect changes in the visual model and weave in new ideas to finalize the model for the incorporation of traditional healers. This final visual model served as a basis for illustrating how relationships were formed as well as a description of the model (Figure 1).

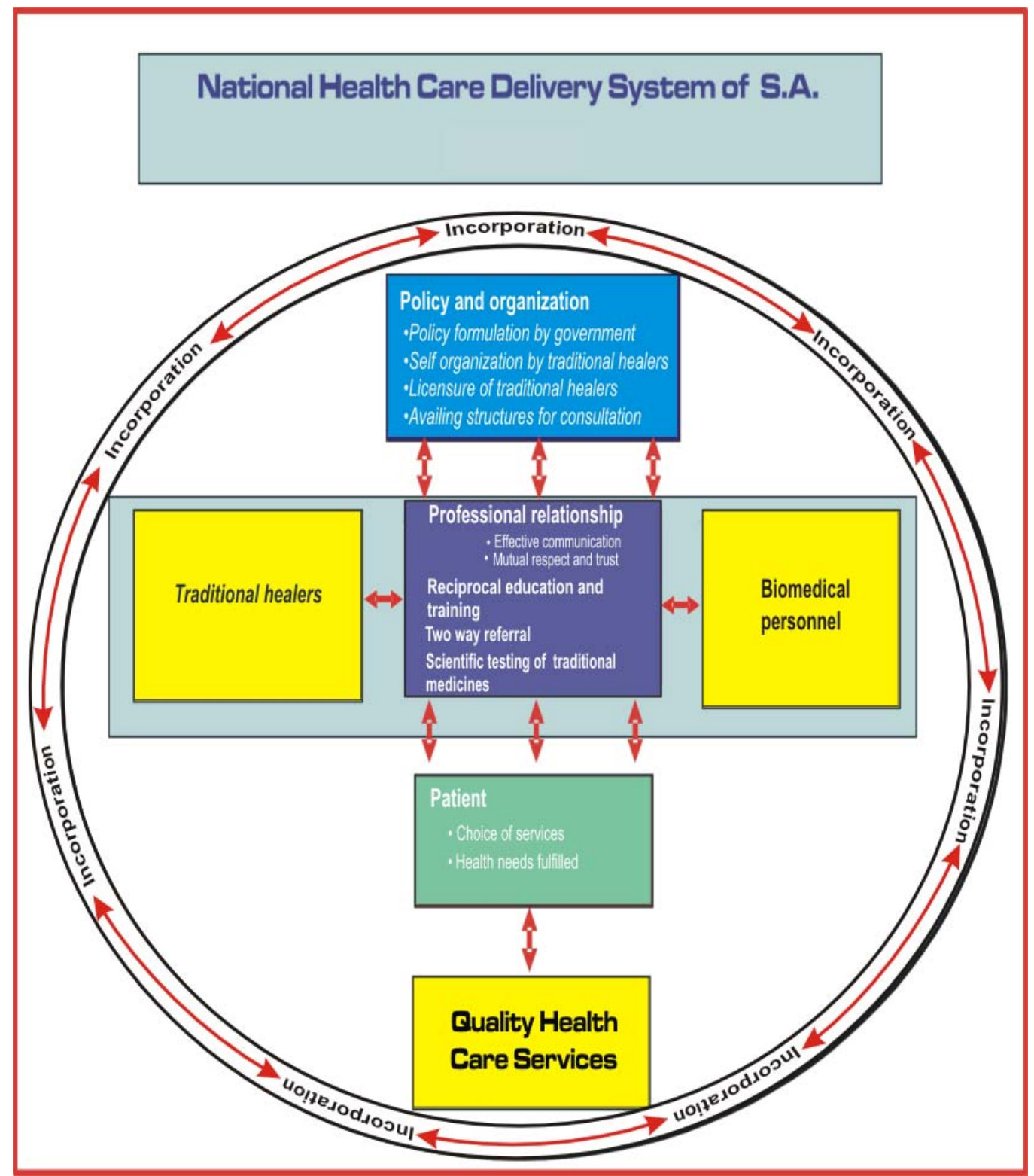

Figure 1: A model for the incorporation of traditional healers into the National Health Care Delivery System of S.A

\section{Discussion}

The purpose of this research was to formulate a model for the incorporation of traditional healers into the National Health Care Delivery System of South Africa. The discussion focuses on the structure and the process of the formulated model to describe an overall picture of what the model consists of.

\section{Structure of the model}

Structuring theory involves forming schematic linkages between concepts which should result in a formal theoretic 
structure which gives a global overall form for the conceptual relationships within. It becomes necessary to start with the most central relationships that are self explanatory and occur between the traditional healer and the biomedical personnel. The two have a professional relationship which evolves around effective communication, mutual respect and trust, reciprocal education and training, two way referral, scientific testing of traditional medicines. The structures are interactive and coalesce in the middle and form relationships evolving around procedures. Concepts are further linked in a linear fashion flowing from policy and organization, to the relationship between traditional healers and biomedical personnel affording the patient a chance to make a choice of a health care delivery system. The patient changes from being ill to attaining a healthy status fulfilling his/her health needs, where the two health care systems are used simultaneously. The totality of the theoretical description for the process of incorporation, demonstrate a circular structure that encompass all the components within the model. The structure takes multiple forms they all link by arrows which portray the interdependence, strength and viability of the relationship that exists between them.

\section{The process of the model for the incorporation}

The process of the model for incorporation of the traditional healers indicates that policy and organization are the first point of departure for the realization of the incorporation process. Policy in this instance is an act formulated by government, stake holders to legalize traditional healing and afford the traditional healers authority and legal status to practice, as is the case with all other health professionals in South Africa. The act was to stipulate clearly the role of the traditional healers in health care settings, indicating their position regarding patient treatment.

Self organization means self control and autonomy for the purpose of effecting internal and external communication. Internal communication is with members, whereby ethical rules and control measures are communicated to them. External communication means the organization act as a spokesperson for its members when communicating with government and or the biomedical personnel. The organization is to ensure that rivalry and jealousy remain under control and engender a feeling of trust among own members and the biomedical personnel. It is the organization that sets standards and guidelines for the practice of traditional healing according to their own frame of reference. The guidelines that are set are to be maintained and used as a yard stick to evaluate traditional practices. Furthermore the organization need to ensure that members are licensed.

Licensing implies that all practicing members are to be in rolls or registers with each member having a registration number to practice. The new initiates are licensed by their master traditional healers who train them. The purpose of licensing is to identify fakes, and enforce ethical control over the practice of traditional healing, and give each member an opportunity to sell his/her medicines. The organization should communicate mandatory yearly renewal of licenses and that failure to update membership means no practice for that year. All other traditional healers without licenses should face harsh sentencing if no one is answerable for their existence as traditional healers.

Safe structures for consultation should be built for traditional healers and to be near the taxi rank for easy access to transport as well as near the clinics/hospital to enhance the process of referral between the traditional healers and the biomedical personnel. The traditional healer who is in the rural areas need their structures to be reinforced to withstand the elements, and these should be maintained by government in the same fashion as for the urban traditional healers.

Effective communication is important to foster a professional relationship between traditional healers and biomedical personnel. This professional relationship is strengthened where information shared enables understanding of each other's world, treatment methods and agree on modus operandi to effect incorporation. Opening up to each other enhances mutual respect and trust and reduces the notion of witchcraft associated with traditional healing.

Reciprocal education and training takes place through workshops and information sharing sessions whereby traditional healers teach biomedical personnel some traditional healing therapies, and traditional healers are taught some basic biomedical practices, like basic personal and environmental hygiene, treatment of cases within their scope, identification and referral of complications, doses for administration of herbal medicines, nature conservation and compiling their own book of herbal remedies. Traditional healers need to be evaluated to determine their level of competency and those who pass are to be given an opportunity to work in health care settings. Biomedical personnel are taught some traditional techniques like home protection, removal of bad luck or repugnancy, steam bathing and performance of some rituals and ceremonies. In this whole process the biomedical personnel acknowledge the contribution of the traditional healers and need to trust the therapeutic techniques because the veil of secrecy is removed.

A two way referral system is facilitated based on shared information regarding the progress of the patient. The biomedical personnel reciprocate the referral by identifying cases which fail to respond to biomedical treatment and send patients to traditional healers. The referral letter should inform the other the treatment initiated and the progress or regress noted. During referral the patient is allowed to take the prescribed treatment and communicate this to the referred practitioner to avoid problems of toxicity or duplication of regime.

Avail new and untested medicines for scientific testing to be undertaken by traditional medicines to all health care settings. Each tested medicine should have an information leaflet which makes the user to know effects and side effects and signs of over dosage, toxic reactions and emergency interventions. These medicines are to be dispensed by traditional healers and/or biomedical personnel who received training in traditional therapeutic techniques. Traditional healers who bring useful medicines are to be acknowledged duly and their ownership right to remain protected.

The patient have a choice in deciding on whom to consult to fulfil his/her health needs. The patients are to be treated with respect, human dignity, tolerance, acceptance, empathy, patience and are to be supported when deciding to consult the traditional healers. The patients should be more open to biomedical personnel regarding consulting the traditional healers and are not to 
exhibit any fear or inhibitions regarding availing developments and progress of his/her health to biomedical personnel as well as to the traditional healers.

Availing quality health care service to the patients using the principles of primary healthcare which are, accessibility, acceptability, affordability, sustainability and inter-sectoral collaboration.

Accessibility implies that the traditional healer has consulting rooms near the taxi rank, clinic or hospital, so that when his services are needed he is within reach or when complications arise he/she is able to ferry the patient to the clinic or hospital with ease.

Acceptability is reflected by accepting and acknowledging the services rendered by both practitioners under the aura of respect and trust engendered by effective communication, where the patient exercises his/her right to choose which of the two service providers to use at that time.

Affordability means payments to both practitioners should be reasonable, the traditional healers to standardize payments, reach an agreement about the amount and the manner of payment.

Sustainability is ensured by safeguarding the practice of traditional healers against fakes, whereby those in practice are licensed and the areas where they render their services are known, safe and protected against criminal elements.

Inter-sectoral collaboration is maintained by involving the traditional healers when consulting with other sectors and biomedical personnel regarding all health matters.

Evaluation of the Model for the incorporation of traditional healers into the National Health Care Delivery System of South Africa

A combination of the criteria of Hardy (1978); Greeff (1991) and Chinn and Kramer (1995) was used to structure the evaluation using the following, clarity, simplicity, accessibility, generality and importance.

\section{Clarity}

Clarity was evaluated by looking for both semantic and structural components as is the case with this research. Semantic clarity Semantic implies the meaning of words, and clarity means quality of being expressed meaningfully. In this research semantic clarity evaluates important aspects related to clarity in the definition of the main and associated concepts The main concept was analysed and defined according to dictionaries and subject definitions. The model can be understood regarding how ideas were conceptualized and those that were not clear were identified and redefined to enable the researcher to make the model easy to understand.

\section{Structural clarity}

Structural clarity is closely associated with semantic clarity because it addresses the way in which logic and reasoning were applied in the theory. Concepts are arranged and organized meaningfully in a linear, horizontal, and vertical upwards and downwards fashion. The relationships between the traditional healers, biomedical personnel evolve around the activities that are interactive which are to be undertaken to effect incorporation and avail quality health services to the patient.

\section{Simplicity}

Evaluating simplicity means that the number of elements within each descriptive category, particularly concepts and their relationship should be minimal, with fewer relational components. This model is very simple and the concepts identified and classified show their relationship one to the other and are not standing in isolation.

\section{Accessibility}

Accessibility addresses identified concepts within the model as well as attainable research outcomes. The research is in six articles which are to be availed, making the attained objectives a reality. This model is for incorporation of traditional healers, and is to be accessed by health departments for availing the services of both the traditional healers and biomedical personnel to fulfil the patients health needs.

\section{Generality}

Generality means that a theory covers a broad spectrum of concepts but is still relatively simple and valid. This theory has a potential for generalization as it can be converted from its contextual nature as undertaken in three of the nine provinces in South Africa. Further the model has a breadth and scope to be used for urban and rural environment because patients remain as recipients and consumers of services from both the traditional healers and biomedical personnel.

\section{Importance}

Importance addresses the extend to which a theory leads to valued nursing goals. This model is unique based on the 
premise that no model has ever been formulated for incorporation of traditional healers into the South African National Health Care Delivery System. Furthermore the patient has an opportunity to make a choice regarding whom to consult for his/her health needs. Incorporation of the traditional healer is important to ensure quality health care service using the principles of primary health care.

\section{Conclusion}

This is the conclusion of the article briefly describing stage one and detailing stage two, where the final objective to formulate a model for the incorporation of traditional healers into the National Health Care Delivery System of South Africa is attained. The formulated model shows the government formulating policy to legalize traditional healing and affords the traditional healers legal authority be an official partner to the biomedical personnel and avail the quality health care services that fulfils the patients health needs using the primary health care approach.

\section{Acknowledgements}

The Vaal Triangle Technikon now the Vaal University of Technology, the North-West University School of Nursing Science for financial, academic and scholarly guidance throughout this research 1997-2005;

The three provinces of North West, Gauteng and Free State health departments for consenting and enabling me to undertake the research; The participants: traditional healers; biomedical personnel as nurses , doctors, pharmacists, psychologists and psychiatrists; deputy directors, health services managers as policy makers and patients, all without whom this study would not have been feasible.

\section{References}

1. Abdool Karim, S.S; Ziqubu -Page, T.T \& Arendse, R. (1994). Bridging the gap: Potential for health care partnership between African traditional healers and biomedical personnel in South Africa. South African Medical Journal, December, 84 (2): 1-16

2. Burns, N. \& Grove, S.K. (1997). The practice of nursing research: Conduct, Critique and Utilization. Philadelphia: W.B. Saunders.

3. Chinn, P. L \& Kramer, M.K. (1995) Theory and Nursing: A systematic approach. St. Louis: Mosby Year book.

5. Department of Health (1996). Annual Report. Pretoria: Government Printers. $60 \mathrm{p}$.

6. Department of Health. (1997). White Paper for the transformation of health systems in South Africa. (Notice 667). Government Gazette, 17:910-1. April 16. 232 p.

7. Department of Health. (2000). Guidelines for Good Practise in the Conduct of the Clinical Trials in Human participants in South Africa. Pretoria: Government Printers.

8. Department of Health. (2003-2007) The Traditional Health Practitioners Act. (Notice 979). Government Gazette, 24704. April. 11. 3-36.

9. Dickoff, S., James, P. \& Wiedebach, E. (1968). Theory in a practice discipline. Part 1. Practice orientated theory. Nursing Research, 17 (5) Sept - Oct 1968: $415-435$.

10. Greeff, M. (1991). 'n Model vir psigiatriese verpleegkundige begeleiding van die pasiente met geestesongemaak. Johannesburg: RAU. ( A doctoral theses.)

11. Hardy, M.E. (1978). Theoretical Foundations For Nursing. New York: MSS Information corporation.

12. Peu, M.D., Troskie, R. \& Hatting, S.P. (2001). Attitude of community health nurses towards integration of traditional healers in Primary Health Care in North West Province. Curationis, 25(1) 49-55.

13. Pinkoane, M. G. Greeff, M \& Williams, M.S.J. (2001). Patient relationship and therapeutic techniques of the South Sotho traditional healer. Curationis. 28(4) 20-30.

14. Pinkoane, M.G., Greeff, M. \& Koen, M.P. (2005a). Models for the incorporation of traditional healers into the National Health Care Delivery System: A literature review . Unpublished Theses (Article 1). Potchefstroom. North West University.

15. Pinkoane, M.G., Greeff, M. \& Koen, M.P. (2005b). Traditional healers' perceptions and attitudes regarding the incorporation of traditional healers into the National Health Care Delivery System of South Africa. Unpublished Theses (Article 2). Potchefstroom. North West University.

16. Pinkoane, M.G., Greeff, M. \& Koen, M.P. (2005c). The biomedical personnel's perceptions and attitudes regarding the incorporation of traditional healers into the National Health Care Delivery System of South Africa. Unpublished Theses (Article 3). Potchefstroom. North West University.

17. Pinkoane, M.G., Greeff, M. \& Koen, M.P. (2005e). Policy makers' perceptions and attitudes regarding the incorporation of traditional healers into the National Health Care Delivery System of South Africa. Curationis. 30 (4)15-29.

18. Tesch, G (1990). Research design: qualitative and quantitative approaches. (In Cresswell, J. Ed. A qualitative approach. Library of congress catalogues in publication data.133 - 157.)

19. World Health Organization. (1987). Traditional healers as community health care workers. A review of projects using traditional healer as Community Health Care worker. Geneva.

20. World Health Organization. (2000). Promoting the role of traditional medicine in health systems: a strategy for the African region. 20012010. Harare: WHO regional office for Africa.

21. Wilson, H.S. (1989). Research in Nursing. California: Addison Wesley.

22. Zungu Chief. (1992). Should traditional healers be recognised and registered/ If so, how should this occur? Centre for Health Policy. University of Witwatersrand.17p. 